\title{
THE NON-OPTIMALITY OF PROPOSED MONETARY POLICY RULES UNDER TIMELESS-PERSPECTIVE COMMITMENT
}

\author{
Christian Jensen \\ Bennett T. McCallum \\ Working Paper 8882 \\ http://www.nber.org/papers/w8882 \\ NATIONAL BUREAU OF ECONOMIC RESEARCH \\ 1050 Massachusetts Avenue \\ Cambridge, MA 02138 \\ April 2002
}

The authors are indebted to Edward Nelson, Lars Svensson, and Alexander Wolman for helpful suggestions. The views expressed herein are those of the authors and not necessarily those of the National Bureau of Economic Research.

(C) 2002 by Christian Jensen and Bennett T. McCallum. All rights reserved. Short sections of text, not to exceed two paragraphs, may be quoted without explicit permission provided that full credit, including (C) notice, is given to the source. 
The Non-Optimality of Proposed Monetary Policy Rules Under

Timeless-Perspective Commitment

Christian Jensen and Bennett T. McCallum

NBER Working Paper No. 8882

April 2002

JEL No. E52, E58, E30

\section{ABSTRACT}

Several recent papers have usefully emphasized the inefficiency that arises from discretionary monetary policymaking, relative to optimal policy from a "timeless perspective," in macroeconomic models with forward-looking private behavior. The inefficiency in question is in terms of average outcomes of the conditional expectation of a policy objective that reflects the discounted present value of current and future period losses (which involve squared deviations of inflation and output from specified target levels). In the literature, most of the analysis has been conducted in an optimizing model that features a Calvo-Rotemberg price adjustment equation that includes a "cost-push" shock term. This literature suggests that policy, which keeps inflation equal to a negative multiple of the change in the output gap, is optimal with respect to the criterion mentioned above - the unconditional expectation of the policymaker's objective function. Results reported here show, however, that this is not the case - that an alternative policy rule, suggested by the approach of "policy design" rather than by "optimal control," delivers superior results.

Christian Jensen

Graduate School of Industrial Administration

Carnegie Mellon University

Pittsburgh, PA 15213

(412) 421-6064

cjensen@andrew.cmu.edu
Bennett C. McCallum

Graduate School of Industrial Administration

Carnegie Mellon University

Pittsburgh, PA 15213

and NBER

(412) 268-2347

bm05@andrew.cmu.edu 
Several recent papers, some quite prominent, ${ }^{1}$ have usefully emphasized the inefficiency that arises from discretionary monetary policymaking, relative to optimal policy from a "timeless perspective," in macroeconomic models with forward-looking private behavior. The inefficiency in question is in terms of average outcomes of the conditional expectation of a policy objective that reflects the discounted present value of current and future period losses (which involve squared deviations of inflation and output from specified target levels). "Forward-looking" in the statement above means that expectations of future variables (e.g., inflation) appear in structural relations representing private behavior. In the literature in question, most of the analysis has been conducted in an optimizing model that includes a price adjustment equation of the Calvo-Rotemberg type, often referred to as a New Keynesian Phillips Curve, that includes a "cost-push" shock term.

Policy from a timeless perspective reflects a type of commitment, on the part of the optimizing monetary policymaker, that avoids influences from the conditions that happen to prevail at the date at which the posited type of policy behavior begins. It is therefore arguably more credible than policy behavior that has the central bank planning to behave differently in the policy's initial period than in those to follow (as with ordinary commitment choices). It has the feature of being time-consistent from its own perspective, although not from the viewpoint of Kydland and Prescott (1977). ${ }^{2}$ The literature seems to suggest that policy satisfying stated conditions — exemplified by (5) below—is optimal with respect to the criterion mentioned above, the unconditional expectation of the policymaker's objective function. It has recently been shown by Jensen (2001a), however, that this is not the case-

\footnotetext{
${ }^{1}$ Among the more prominent papers are those of Clarida, Gali, and Gertler (1999), H. Jensen (1999), and Woodford (1999a, 1999b, 2000, 2001). Other significant items include Dennis (2001), Gianonni (2001), McCallum and Nelson (2000), Steinsson (2000), Svensson and Woodford (1999), Vestin (2000), and Walsh (2001).
} 
that an alternative policy rule, suggested by the approach of "policy design" rather than by "optimal control," delivers superior results. ${ }^{3}$ The magnitude of improvement is not large, for realistic parameter values, but is distinctly non-zero. The purpose of the present note is to provide a compact description and demonstration of this particular result of Jensen's (2001a).

Following Clarida, Gali, and Gertler (CGG, 1999), H. Jensen (1999), Woodford (1999a, 1999b), and others, suppose that price adjustment behavior is given by

$$
\pi_{\mathrm{t}}=\beta \mathrm{E}_{\mathrm{t}} \pi_{\mathrm{t}+1}+\alpha \mathrm{y}_{\mathrm{t}}+\mathrm{u}_{\mathrm{t}}, \quad \alpha>0,0<\beta<1,
$$

where $\pi_{\mathrm{t}}$ is inflation, $\mathrm{y}_{\mathrm{t}}$ is the output gap, and $\mathrm{u}_{\mathrm{t}}$ is a stochastic shock term that is assumed to be autoregressive of order one with $\mathrm{AR}$ parameter $\rho$ and innovation variance $\sigma^{2}$. By the output gap we mean the fractional difference between realized output and the flexible-price or natural-rate level of output.

The policymaker's objective at an arbitrary time $\mathrm{t}=1$ is to minimize

$$
\mathrm{E}_{1} \sum_{\mathrm{t}=1}^{\infty} \beta^{\mathrm{t}-1}\left(\pi_{\mathrm{t}}^{2}+\omega \mathrm{y}_{\mathrm{t}}^{2}\right)
$$

where $\omega \geq 0$ reflects the relative importance of output-gap variability in policymaker preferences. ${ }^{4}$ The macroeconomic model that we have in mind also includes an optimizing IS-type relationship of the form

$$
\mathrm{y}_{\mathrm{t}}=\mathrm{E}_{\mathrm{t}} \mathrm{y}_{\mathrm{t}+1}+\mathrm{b}\left(\mathrm{R}_{\mathrm{t}}-\mathrm{E}_{\mathrm{t}} \pi_{\mathrm{t}+1}\right)+\mathrm{v}_{\mathrm{t}}, \quad \mathrm{b}<0,
$$

where $R_{t}$ is the central bank's interest rate instrument and $v_{t}$ is a shock that pertains to preferences, government spending, and the exogenous natural-rate value of output. But we shall suppose, as in much of the literature under discussion, that the central bank (CB) can

\footnotetext{
${ }^{2}$ See Woodford (1999b, pp. 293-4) for further details on the timeless perspective.

${ }^{3}$ Policy design is the term used by Prescott (1977) for a procedure that involves search for optimal policy-rule parameters after solving the model with a policy rule that includes all relevant state variables. The procedure has been used by Taylor (1979), Rotemberg and Woodford (1999), and others.
} 
directly control $\pi_{\mathrm{t}}$ as an instrument - an assumption that is innocuous for the purposes of this note (though not for all issues). Then relation (3) becomes irrelevant, and the policy problem is to minimize (2) subject to the constraint in (1) for the current and all future periods.

The optimality conditions proposed by CGG (1999, p. 1703) and Woodford (1999a, p. 24; 1999b, pp. 305-6), followed by McCallum and Nelson (2000), may be written as follows: $:^{5}$
(4a) $2 \omega y_{t}+\alpha \lambda_{t}=0$
$\mathrm{t}=1,2, \ldots$
(4b) $\quad 2 \pi_{t}-\lambda_{t}+\lambda_{t-1}=0$
$\mathrm{t}=2,3, \ldots$
(4c) $\quad 2 \pi_{t}-\lambda_{t}=0$
$\mathrm{t}=1$.

Here it is arbitrarily assumed that the policy is being initiated (started up) in period $t=1$. But to adopt the timeless perspective, the CB ignores (4c) and applies (4b) in period 1 as well as in $2,3, \ldots$. Substituting out the Lagrangian multiplier yields

$$
\pi_{\mathrm{t}}=-(\omega / \alpha)\left(\mathrm{y}_{\mathrm{t}}-\mathrm{y}_{\mathrm{t}-1}\right)
$$

Thus the behavior of $\pi_{\mathrm{t}}$ and $\mathrm{y}_{\mathrm{t}}$ is governed, under the proposed timeless perspective commitment policy, by relations (1) and (5) for periods $t=1,2, \ldots$

The minimum-state-variable (MSV) solution ${ }^{6}$ for this system is of the form

$$
\begin{aligned}
& \text { (6) } \pi_{\mathrm{t}}=\phi_{11} \mathrm{y}_{\mathrm{t}-1}+\phi_{12} \mathrm{u}_{\mathrm{t}} \\
& \text { (7) } \mathrm{y}_{\mathrm{t}}=\phi_{21} \mathrm{y}_{\mathrm{t}-1}+\phi_{22} \mathrm{u}_{\mathrm{t}},
\end{aligned}
$$

and the coefficients can straightforwardly be found to equal $\phi_{11}=(\omega / \alpha)(1-\delta), \phi_{12}=(\gamma-\beta \delta)^{-1}$, $\phi_{21}=\delta$, and $\phi_{22}=-(\alpha / \omega)(\gamma-\beta \delta)^{-1}$, where $\delta=\left[\gamma-\left(\gamma^{2}-4 \beta\right)^{0.5}\right] / 2 \beta$ with $\gamma=1+\beta+\left(\alpha^{2} / \omega\right)^{7}$

\footnotetext{
${ }^{4}$ For notational simplicity, we assume zero to be the target values of inflation and the output gap.

${ }^{5}$ Here $\lambda_{t}$ denotes the Lagrangian multiplier attached to constraint (1) for period $t$.

${ }^{6}$ See McCallum (1999) for an extensive discussion of this solution concept.

${ }^{7}$ See McCallum and Nelson (2000, pp. 7-8).
} 
This solution agrees with those of CGG (1999) and Woodford (1999b, pp. 295, 307), and is dynamically stable (so $\mathrm{E} \pi_{\mathrm{t}}=0$ and $\mathrm{Ey} \mathrm{t}_{\mathrm{t}}=0$ ).

To summarize policy performance, CGG (1999), Woodford (1999a, 1999b), and McCallum and Nelson (2000) report average values of the loss function (2), i.e., values of the unconditional expectation of (2). Because of the law of iterated expectations, that expression equals (2) with $E$ replacing $E_{1}$. Then taking $E$ inside the summation operator, we find that the result equals $(1-\beta)^{-1}$ times the unconditional expectation of the single-period loss, $\mathrm{E}\left(\pi_{\mathrm{t}}^{2}+\omega \mathrm{y}_{\mathrm{t}}^{2}\right)$. That equality is used here only for evaluation purposes, however; it is not utilized in the derivation (which is not discussed here) of the proposed conditions (4). In the cited papers, the values of the average loss criterion just described is reported for outcomes with policy rule (5) and compared with values resulting when (5) is replaced with the optimal discretionary policy condition, which is

$$
\pi_{\mathrm{t}}=-(\omega / \alpha) \mathrm{y}_{\mathrm{t}}
$$

as shown by CGG (1999), Woodford (1999a, 1999b), or McCallum and Nelson (2000). In all of their reported cases, the average loss with (5), henceforth denoted L(5), is smaller than that obtained with rule (8).

What Jensen (2001a) demonstrates, however, is that (5) does not yield the smallest average loss, even if attention is restricted to rules (i.e., conditions for $\pi_{\mathrm{t}}$ ) including the same variables as (5). Specifically, if policy is conducted according to

$$
\pi_{\mathrm{t}}=-(\omega / \alpha)\left(\mathrm{y}_{\mathrm{t}}-\beta \mathrm{y}_{\mathrm{t}-1}\right)
$$

then average values of (2) are smaller. ${ }^{8}$ Table 1 below reports some representative results for L(5) and (analogously-defined) L(9) for various values of the parameters $\omega, \beta$, and $\rho$, given

\footnotetext{
${ }^{8}$ Since writing this note, we have learned that a very recent paper by Blake (2001) also reports this result.
} 
$\alpha=0.02$ and $\mathrm{E}\left(\mathrm{u}_{\mathrm{t}}{ }^{2}\right)=\left(1-\rho^{2}\right)^{-1} \sigma^{2}=(0.005)^{2}{ }^{2}$. Since our calibration implicitly assumes quarter-year time periods, and outcomes are reported in fractional units, the value of 0.0625 for $\omega$ represents equal weights on $\pi_{\mathrm{t}}^{2}$ and $\mathrm{y}_{\mathrm{t}}^{2}$ in the objective function. It is clear from the numbers in Table 1 that policy rule (9) provides smaller losses than does (5) over a wide range of parameter magnitudes. The difference is greater when $\beta$ is smaller, of course, and when $\rho$ is large.

A few words are needed concerning optimization conditional upon initial conditions. It is widely recognized that condition (5) fails to minimize (2), given $\mathrm{y}_{0}$ and $\mathrm{u}_{1}$, if applied in $\mathrm{t}$ $=1$ as well as $\mathrm{t}=2,3, \ldots{ }^{10}$ Jensen (2001a) points out that, in addition, (5) is not generally optimal within the class of rules - conditions applied in all periods $1,2, \ldots \multimap$ of the same form. With specified values of $\mathrm{y}_{0}$ and $\mathrm{u}_{1}$, for example, one can find a rule including the same variables as (5) that yields a lower value of (2) than does (5), with optimal coefficient values that depend on the initial conditions. As an example, suppose that $\mathrm{y}_{0}=0.03$ and $\mathrm{u}_{1}=-0.01$ with $\omega=0.0625, \rho=0.5$ and $\beta=0.99$. Then (5) yields a loss value for (2) of 0.008878 whereas the use of

$$
\pi_{t}=-2.617 y_{t}+2.502 y_{t-1}
$$

results in a loss of $0.008658 .{ }^{11}$ This example illustrates that (5) does not minimize (2) when the same condition must be used in all periods, at least not in general. ${ }^{12} 13$

\footnotetext{
${ }^{9}$ This last magnitude is of no importance; changing it would scale all the values in Table 1 up or down proportionately.

${ }^{10}$ See, among others, Woodford (1999b), Svensson and Woodford (1999), King and Wolman (1999), and Dennis (2001).

${ }^{11}$ Calculation of these values is discussed by Jensen (2001b). All reported results use the MSV solution.

${ }^{12}$ Condition (5) is optimal in this case if $\mathrm{y}_{0}=0$, but not otherwise.

${ }^{13}$ No table is provided since it would require extensive computation and a single example suffices to make the point at issue.
} 
Overall, our point is not that there is anything conceptually wrong with the timeless perspective type of policy making, in which the initial period policy reaction function is constrained to be the same as in all succeeding periods, but that (5) is not the optimal condition from this perspective, even if conditions (4) minimize (2). Jensen (2001a) argues that the fashion in which optimality conditions (4) of the unconstrained problem are modified to produce (5) does not give the optimality conditions for the constrained problem. Here our objective is not to put forth any explanation, however, but merely to demonstrate the superiority of rule (9) over the previously-utilized (5) from the perspective of the average value of the loss function (2). We also point out the non-optimality of (5) with respect to objective (2) on a conditional basis, when credible commitment requires that the same policy rule be used in all periods including the one in which the policy regime is introduced. 


\section{Table 1}

\section{Losses with Policy Rules (5) and (9)}

[Reported values are losses times $10^{3}: \mathrm{L}(5) / \mathrm{L}(9)$ ]

\begin{tabular}{|c|c|c|c|c|}
\hline $\begin{array}{c}\text { Value of } \\
\beta \text { and } \rho\end{array}$ & $\omega=0.01$ & $\omega=0.0625$ & $\omega=0.10$ & $\omega=1.00$ \\
\hline $0.99,0.0$ & $\begin{array}{c}2.0659 / 2.0656 \\
=1.0002\end{array}$ & $\begin{array}{c}2.330 / 2.329 \\
=1.0004\end{array}$ & $\begin{array}{c}2.369 / 2.368 \\
=1.0006\end{array}$ & $\begin{array}{c}2.473 / 2.469 \\
=1.0017\end{array}$ \\
\hline $0.99,0.5$ & $\begin{array}{c}5.916 / 5.914 \\
=1.0004\end{array}$ & $\begin{array}{c}8.029 / 8.019 \\
=1.0013\end{array}$ & $\begin{array}{c}8.407 / 8.393 \\
=1.0016\end{array}$ & $\begin{array}{c}9.500 / 9.452 \\
=1.0051\end{array}$ \\
\hline $0.99,0.9$ & $\begin{array}{c}29.721 / 29.678 \\
=1.0015\end{array}$ & $\begin{array}{c}81.010 / 80.550 \\
=1.0057\end{array}$ & $\begin{array}{c}97.952 / 97.194 \\
=1.0078\end{array}$ & $\begin{array}{c}176.52 / 171.47 \\
=1.0295\end{array}$ \\
\hline $0.98,0.0$ & $\begin{array}{c}1.042 / 1.041 \\
=1.0007\end{array}$ & $\begin{array}{c}1.176 / 1.174 \\
=1.0018\end{array}$ & $\begin{array}{c}1.196 / 1.193 \\
=1.0022\end{array}$ & $\begin{array}{c}1.247 / 1.240 \\
=1.0059\end{array}$ \\
\hline $0.98,0.5$ & $\begin{array}{c}2.980 / 2.974 \\
=1.0018\end{array}$ & $\begin{array}{c}4.046 / 4.025 \\
=1.0050\end{array}$ & $\begin{array}{c}4.235 / 4.208 \\
=1.0064\end{array}$ & $\begin{array}{c}4.772 / 4.690 \\
=1.0174\end{array}$ \\
\hline $0.98,0.9$ & $14.904 / 14.817$ & $\begin{array}{c}40.610 / 39.711 \\
=1.0227\end{array}$ & $\begin{array}{c}49.055 / 47.591 \\
=1.0308\end{array}$ & $\begin{array}{c}86.910 / 78.892 \\
=1.1016\end{array}$ \\
\hline & $=1.0059$ & \multicolumn{3}{c}{} \\
\hline
\end{tabular}




\section{References}

Blake, A.P. (2001) 'A 'timeless perspective' on optimality in forward-looking rational expectations models," Working paper, National Institute of Economic and Social Research, London.

Clarida, R., J. Gali, and M. Gertler (1999) "The science of monetary policy: A new Keynesian perspective," Journal of Economic Literature 37, 1661-1707.

Dennis, R. (2001) "Pre-commitment, the timeless perspective, and policymaking from behind a veil of uncertainty," Working paper, Federal Reserve Bank of San Francisco

Giannoni, M. (2001) “Model Uncertainty and Optimal Monetary Policy,” Doctoral dissertation, Princeton University.

Jensen, C. (2001a) "Optimal monetary policy in forward-looking models with rational expectations," Working paper, Carnegie Mellon University. . (2001b) "Optimal policy in forward-looking models with rational expectations by policy design," Working paper, Carnegie Mellon University.

Jensen, H. (1999) “Targeting nominal income growth or inflation?” Working paper, University of Copenhagen. Forthcoming in American Economic Review.

King, R.G., and A. Wolman, "What should the monetary authority do when prices are sticky?" in J.B. Taylor, ed., Monetary Policy Rules. University of Chicago Press.

Kydland, F.E. and E.C. Prescott (1977) "Rules rather than discretion: The inconsistency of optimal plans," The Journal of Political Economy 85, 473-492.

McCallum, B.T. (1999) "Role of the minimal state variable criterion in rational Expectations models," in P. Isard, A. Razin, and A.K. Rose, eds., International Finance and Financial Crises: essays in honor of Robert P. Flood, Jr. Kluwer Academic Publishers. Also in International Tax and Public Finance 6, 621-639.

McCallum, B.T., and E. Nelson (2000) "Timeless perspective vs. discretionary monetary policy in forward-looking models," NBER WP 7915.

Prescott, E.C. (1977) "Should control theory be used for economic stabilization?" CarnegieRochester Conference Series on Public Policy 7, 13-38.

Rotemberg, J.J., and M. Woodford (1999) "Interest rate rules in an estimated sticky price model," in J.B. Taylor, ed., Monetary Policy Rules. Univ. of Chicago Press. 
Steinsson, J. (2000) "Optimal monetary policy in an economy with inflation persistence," Working paper, Princeton University.

Svensson, L.E.O., and M. Woodford (1999) "Implementing optimal policy through inflation-forecast targeting," Working paper, Princeton University.

Taylor, J.B. (1979) "Estimation and control of an econometric model with rational expectations," Econometrica 47, 1267-1286.

Vestin, D. (2000) "Price-level targeting versus inflation targeting in a forward-looking model," Working Paper, Stockholm University.

Walsh, C.E. (2001) "Speed limit policies: the output gap and optimal monetary policy," Working Paper, University of California, Santa Cruz.

Woodford, M. (1999a) “Optimal monetary policy inertia,” NBER WP 7261.

(1999b) "Commentary: How should monetary policy be conducted in an

era of price stability?" New Challenges for Monetary Policy. Federal Reserve Bank of Kansas City, pp. 277-316.

(2000) "Pitfalls of forward-looking monetary policy," American

Economic Review Papers and Proceedings 90, 100-104.

(2001) Interest and Prices: Foundations of a Theory of Monetary

Policy. Manuscript, Princeton University. 